\title{
Characterization of the Intrarenal Renin-Angiotensin System in Experimental Alport Syndrome
}

Eun Hui Bae, ${ }^{* \dagger}$ Ana Konvalinka, ${ }^{\ddagger}$ Fei Fang, ${ }^{*}$ Xiaohua Zhou, ${ }^{*}$ Vanessa Williams, ${ }^{*}$ Nicholas Maksimowski, ${ }^{*}$ Xuewen Song, ${ }^{\ddagger \uparrow}$ Shao-Ling Zhang, ${ }^{\|}$Rohan John, ${ }^{* *}$ Gavin Y. Oudit, ${ }^{\dagger \dagger}$ York Pei, ${ }^{ \pm \uparrow}$ and James W. Scholey ${ }^{* £ \$}$

From the Department of Medicine, * Institute of Medical Science, University of Toronto, Toronto, Ontario, Canada; the Department of Internal Medicine, Chonnam National University Medical School, Gwangju, Republic of Korea; the Divisions of Nephrology ${ }^{\ddagger}$ and Genomic Medicine, "and the Departments of Medicine ${ }^{\S}$ and Pathology, ** University Health Network, University of Toronto, Toronto, Ontario, Canada; the Faculty of Medicine, ${ }^{\|}$Họtel-DieuHọpital, University of Montreal, Montreal, Quebec, Canada; and the Division of Cardiology, ${ }^{\dagger \dagger}$ Department of Medicine, University of Alberta, Edmonton, Alberta, Canada

Accepted for publication January 22, 2015.

Address correspondence to Eun Hui Bae, M.D., Ph.D., Department of Internal Medicine, Chonnam National University Medical School, Hakdong 8, Dongku, Gwangju 501-757, Republic of Korea. E-mail: baedak@jnu.ac.kr.

\begin{abstract}
Blockade of the renin-angiotensin system attenuates the progression of experimental and clinical Alport syndrome (AS); however, the underlying mechanism(s) remains largely unknown. We evaluated the renin-angiotensin system in 4- and 7-week-old homozygous for collagen, type IV, $\alpha 3$ gene $\left(\mathrm{Col}_{4 \mathrm{~A} 3^{-/-}}\right)$and wild-type mice, a model of AS characterized by proteinuria and progressive renal injury. Renal angiotensin (Ang) II levels increased, whereas renal Ang-(1-7) levels decreased

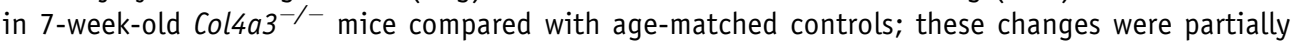
reversed by recombinant angiotensin-converting enzyme 2 (ACE2) treatment. The expression of both the angiotensinogen and renin protein increased in $\mathrm{Col}_{4 \mathrm{a3}^{-/-}}$compared with wild-type mice. Consistent with the Ang-(1-7) levels, the expression and activity of kidney ACE2 decreased in 7-

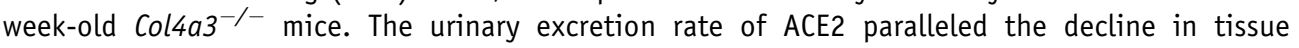
expression. Expression of an Ang II-induced gene, heme oxygenase-1, was up-regulated in the

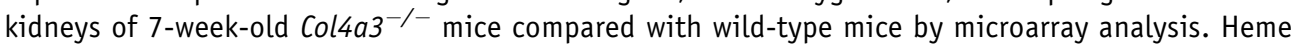
oxygenase-1 (H0-1) protein expression was increased in kidneys of $\mathrm{Col}_{4 a 3^{-/-}}$mice and normalized by treatment with ACE inhibitor. Urinary H0-1 excretion paralleled renal HO-1 expression. In conclusion, progressive kidney injury in AS is associated with changes in expression of intrarenal renin Ang system components and Ang peptides. H0-1 and ACE2 may represent novel markers of AS-associated kidney injury, whereas administration of recombinant ACE2 and/or Ang-(1-7) may represent novel therapeutic approaches in AS. (Am J Pathol 2015, 185: 1423-1435; http://dx.doi.org/ 10.1016/j.ajpath.2015.01.021)
\end{abstract}

Alport syndrome (AS) is a hereditary nephropathy characterized by progressive kidney disease. ${ }^{1,2} \mathrm{AS}$ is caused by mutations in type-IV collagen genes that encode major constituents of glomerular basement membranes. ${ }^{3,4}$ Inhibitors of reninangiotensin system (RAS), including angiotensin-converting enzyme (ACE) inhibitors or angiotensin (Ang) II receptor blockers, were found to slow kidney disease progression in both experimental and clinical AS.,

The effect of RAS blockade, particularly ACE inhibitors, suggests that Ang peptide processing in the kidney is important

\footnotetext{
Supported by operating grants from the Canadian Institutes of Health Research (CIHR), the Kidney Foundation of Canada (KFoC), and the Korea Research Foundation [funded by the Korean Government (MOEHRD) and the Basic Research Promotion Fund grant KRF20100008732]; by funding from the Ontario Graduate Student Program (F.F.); and by a research fellowship from the KFoC and the Clinician Scientist Training Program at the University of Toronto (A.K.). J.W.S. holds a CIHR/AMGEN Chair in Kidney Research at the University of Toronto.

E.H.B., A.K. and F.F. contributed equally to this work.

Y.P. and J.W.S. contributed equally to this work as senior authors.

Disclosures: None declared.
} 
in the pathogenesis of progressive kidney injury in experimental AS. Studies have reported an important role for local Ang peptide processing in tissue responses to RAS activation. In particular, the ACE homolog, ACE2, may play a critical role, through Ang II degradation or Ang-(1-7) generation. The expression and activity of ACE2 were found to modulate the kidney response to injury in settings as diverse as ischemia reperfusion injury, unilateral ureteral obstruction, and diabetic nephropathy. ${ }^{7-9}$

To better understand the mechanism that link RAS activation to injury in AS, we characterized gene and protein expression of RAS components in the kidney of mice homozygous for collagen, type IV, $\alpha 3$ gene $\left(\mathrm{Col}_{4 a 3^{-/}}\right)$, with a focus on ACE2 tissue expression, activity, and urinary excretion. We also measured plasma and intrarenal Ang II and Ang-(1-7) peptide levels and correlated these peptide levels with a previously described Ang II gene/ protein signature. ${ }^{10}$ Our work finds diminished ACE2 expression and activity in kidneys of $\mathrm{Col}_{4} \mathrm{a}^{-/-}$mice, associated with increased Ang II and decreased Ang-(1-7) levels. These abnormalities are further associated with increased tissue and urine levels of Ang II gene/protein signature and can be partially corrected by treatment with recombinant ACE2 (rACE2).

\section{Materials and Methods}

\section{Ethics Statement}

All experiments were conducted according to the guidelines of the University of Toronto Animal Care Committee.

\section{Animals}

Wild-type (WT) and Col4a3 ${ }^{-/-}$knockout (KO) mice on 129X1/SvJ background were purchased from The Jackson Laboratory (Bar Harbor, ME), housed at the Division of Comparative Medicine at the University of Toronto, and fed standard mouse chow with free access to water. Only male mice were used in this study. Genotype for $\mathrm{Col} 4 a 3^{-/-}$mice was verified by tail clip genotyping by using the following primers: common, $5^{\prime}$-CCAGGCTTAAAGGGAAATCC- ${ }^{\prime}$; WT reverse, 5'-TGCTCTCTCAAATGCACCAG- ${ }^{\prime}$; and mutant reverse, 5'-GCTATCAGGACATAGCGTTGG-3' .

\section{Biochemistry}

Blood samples were collected from carotid artery with Microvette (Sarstedt Inc., Montreal, QC, Canada) at time of sacrifice. Serum was isolated by centrifuging blood samples at $2000 \times g$ for 5 minutes at room temperature and stored at $-80^{\circ} \mathrm{C}$ until use. Serum creatinine assessments were done at the Toronto Centre for Phenogenomics (Toronto, ON, Canada). Albumin excretion rates were determined from 24-hour urine collections in 4- and 7-week-old mice with the use of kits (Albuwell M ELISA; Exocell, Philadelphia, PA).

\section{Histology and Immunohistochemistry}

The right kidney was harvested and transversely sectioned into three approximately equal portions. The two polar portions were snap-frozen, and the middle portion was placed into $10 \%$ neutral-buffered formalin (Sigma-Aldrich, St. Louis, MO) for histology and immunohistochemistry analyses. Fixed kidney tissue was paraffin-embedded, sectioned, stained, and scanned. Periodic acid-Schiff-stained sections $(3 \mu \mathrm{m})$ were used to assess histopathologic injury. The following primary antibodies were used for immunohistochemistry: ACE and renin (Santa Cruz Biotechnology, Santa Cruz, CA), ACE2 (R\&D Systems, Minneapolis, MN), and angiotensinogen (AGT) and heme oxygenase-1 (HO-1; Abcam, Inc., Cambridge, MA). Quantitation of ACE and ACE2 on positively stained area was measured by a Positive Pixel Count algorithm of Aperio Image Scope software version 11.1 (Aperio Technologies, Inc., Vista, CA). Semiquantitative analysis was performed for HO-1 stain by counting the average number of positively stained tubules within 10 high-power fields of the renal cortex.

\section{Microarray}

We performed global gene profiling of renal cortical samples from male $\mathrm{Col}_{4 a 3^{-/-}}$mice and WT mice at 4 and 7 weeks of age in a $2 \times 2$ factorial design ( $n=8$ per group). Gene expression was analyzed with the Affymetrix Mouse Gene 2.0 ST array (Affymetrix, Santa Clara, CA). Renal cortex was resected and incubated in RNAlater at $4^{\circ} \mathrm{C}$ overnight and then stored at $-80^{\circ} \mathrm{C}$ until further analyses. Probes were synthesized and labeled with Ambion WT Expression, GeneChip WT Terminal Labeling kits (Ambion, Austin, TX). Affymetrix Mouse Gene 2.0 ST array that feature probe sets for 28,137 coding transcripts, 7103 noncoding transcripts, 2000 long intergenic noncoding transcripts was used for the microarray study. Affymetrix Expression Console software version 1.3.1 was used to assess microarray data quality and to perform RNA signal value normalization.

\section{Ang II and Ang-(1-7) Peptide Measurement}

The concentration of plasma and renal parenchymal Ang II and Ang-(1-7) were determined by Ang II and Ang-(1-7) enzyme immunoassay kits (Peninsula Laboratories, LLC, San Carlos, CA). According to the manufacturer, the Ang II-binding antibody does not cross-react with Ang I or Ang(1-7), and Ang-(1-7)-binding antibody also does not cross-react with Ang I or Ang II. Tissue was prepared as follows: snap-frozen kidney tissue was homogenized in icecold methanol on ice and centrifuged at $12,000 \times g$ for 10 minutes at $4{ }^{\circ} \mathrm{C}$. The supernatant fluid was collected and dried by centrifugal evaporation. Dried samples were reconstituted with the enzyme immunoassay buffer supplied by the manufacturer and used for Ang II and Ang(1-7) measurement. Protein concentrations were determined by the Bradford assay (Bio-Rad Laboratories, Inc., 

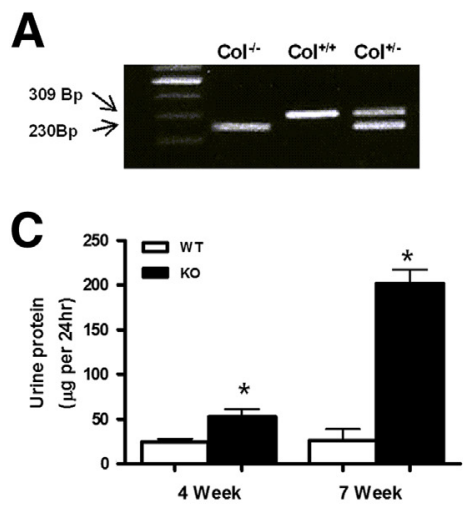

E

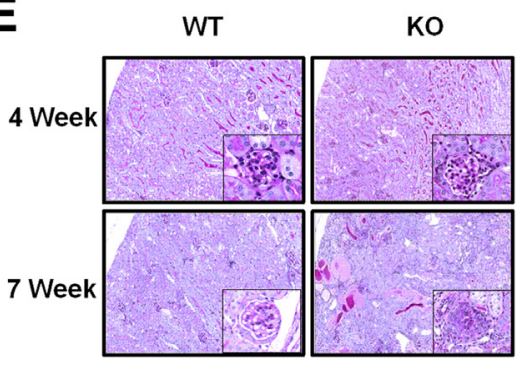

B

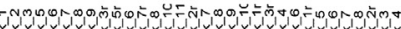

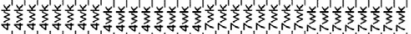

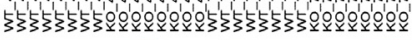
100.6-tis:

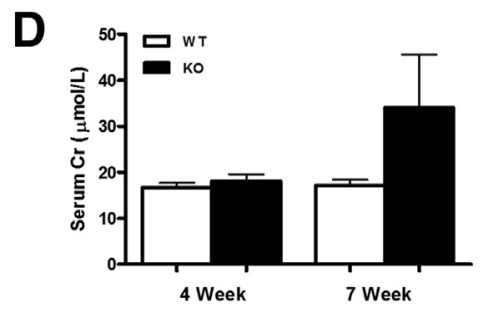

$\mathbf{F}$

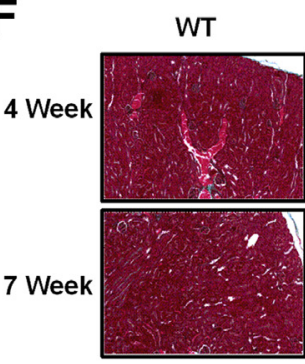

Hercules, CA) from the reconstituted samples and used for normalization.

\section{Real-Time PCR}

RNA was extracted from kidney cortex by using the RNeasy Mini kit and was reverse transcribed into cDNA with the QuantiTect Reverse Transcription kit (Qiagen Canada, Mississauga, ON, Canada). mRNA expression levels for renin, AGT, ACE, ACE2, Ang II type 1 receptor (AT-1R), and Mas receptor (MasR) were quantified by realtime PCR (TaqMan) by using a sequence detection system (ABI Prism 7900; Applied Biosystems, Foster City, CA) as previously described. ${ }^{11}$ Specific mouse primer sets were purchased from Applied Biosystems.

\section{Western Blot Analysis}

Mouse kidney tissue was washed with ice-cold phosphatebuffered saline twice. Renal tissue was placed in modified RIPA buffer at a concentration of $1 \mathrm{mg} / 50 \mu \mathrm{L}$ buffer [150 $\mathrm{mmol} / \mathrm{L}$ sodium chloride, $50 \mathrm{mmol} / \mathrm{L}$ Tris- $\mathrm{HCl}(\mathrm{pH}$ 7.4), 1 $\mathrm{mmol} / \mathrm{L}$ EDTA, $1 \% \mathrm{v} / \mathrm{v}$ Triton X-100, $1 \% \mathrm{w} / \mathrm{v}$ sodium deoxycholic acid, $0.1 \%$ v/v SDS]. Tissues were then sonicated twice for 10 seconds and incubated on ice for $30 \mathrm{mi}-$ nutes. After centrifugation at $14,000 \mathrm{rpm}$ for 10 minutes, supernatant fluid was transferred to a tube with loading buffer and boiled for 5 minutes. Proteins in tissue lysates were separated by $6 \%$ to $12 \%$ SDS-PAGE gel, blotted onto polyvinylidene difluoride membrane and detected with an enhanced chemiluminescence system kit (Millipore Corp., Billerica, MA). Densitometry was calculated by Scion Image software (Scion Corp., Frederick, MD). The following primary antibodies were used for Western blot analyses: ACE,
Figure 1 PCR genotyping for the mice used in the study (A) and the heat map for collagen IV $\alpha 1-\alpha 5$ gene expression in kidney tissue derived from the microarray analysis of 4- and 7-week-old WT and Col4a3 ${ }^{-/-}$mice (KO) (B). Urinary albumin excretion is significantly increased from 4 weeks in the $\mathrm{Col}_{4 a 3^{-1-}}$ (KO) mice (C), whereas serum $\mathrm{Cr}$ is nonsignificantly increased at 7 weeks (D). Histopathologic injury in the kidney is evident in the PAS-stained (E) and Masson's trichrome-stained (F) sections. Tubule dilatation and tubulointerstitial scarring are particularly prominent in the $\mathrm{Col}_{4 \mathrm{O}^{-/-}}$mice at 7 weeks of age compared with the WT mice. Insets in $\mathbf{E}$ show the glomerulus. Data are expressed as means \pm SEM. ${ }^{*} P<0.05$ versus WT. Original magnification: $\times 100(\mathbf{E}$ and $\mathbf{F})$; $\times 200$ (insets). Col, collagen; Col $4 a 3^{-/-}$, homozygous for collagen, type IV, $\alpha 3$ gene; $\mathrm{Cr}$, creatinine; KO, knockout; PAS, periodic acid-Schiff; WT, wild-type.
AT-1R, renin, and MasR (Santa Cruz Biotechnology); ACE2 (R\&D Systems); AGT and HO-1 (Abcam, Inc.).

\section{ACE Activity}

Kidney ACE activity was measured by the rate of generation of His-Leu from Hip-His-Leu (Sigma-Aldrich) substrate by using fluorometric assay. Tissue was homogenized in ice-cold 50 $\mathrm{mmol} / \mathrm{L}$ potassium phosphate buffer, $\mathrm{pH}$ 7.5. An aliquot of the homogenized samples was then incubated with $3.5 \mathrm{mmol} / \mathrm{L}$ Hip-His-Leu for 10 minutes in $37^{\circ} \mathrm{C}$ shaking water bath. The reaction was stopped by adding $340 \mathrm{mmol} / \mathrm{L} \mathrm{NaOH}$. Blank controls were treated in the same fashion, with the exception that Hip-His-Leu was added after sodium hydroxide treatment. We added $1 \%$ phthalaldehyde (Sigma-Aldrich) to the aliquots for 10 minutes before the color reaction was stopped with $3 \mathrm{~N}$ $\mathrm{HCl}$. Fluorescence was measured with an FLX800 microplate fluorescence reader (BioTek Instruments Inc., Winooski, VT) at $355 \mathrm{~nm}$ of excitation and $520 \mathrm{~nm}$ of emission wavelength.

\section{ACE2 Activity}

Kidney ACE2 activity was determined after incubation with the intramolecularly quenched synthetic ACE2-specific substrate Mca-APK-Dnp (Anaspec, Inc., Fremont, CA). The measurements were performed in black microtiter plates with a $100-\mu \mathrm{L}$ total volume. Briefly, $1 \mu \mathrm{g}$ of total protein from tissue homogenate (renal cortex) was added to wells that contain $10 \mu \mathrm{mol} / \mathrm{L}$ ACE2 substrate. After incubation at ambient temperature for 1 hour, fluorescence was measured with an FLX800 microplate fluorescence reader (BioTek Instruments Inc.) at $330 \mathrm{~nm}$ of excitation and $390 \mathrm{~nm}$ of emission wavelength. Total fluorescence was corrected for protein content (in tissue homogenates) after subtracting blank values. 
Table 1 Mouse Data and Functional Parameters

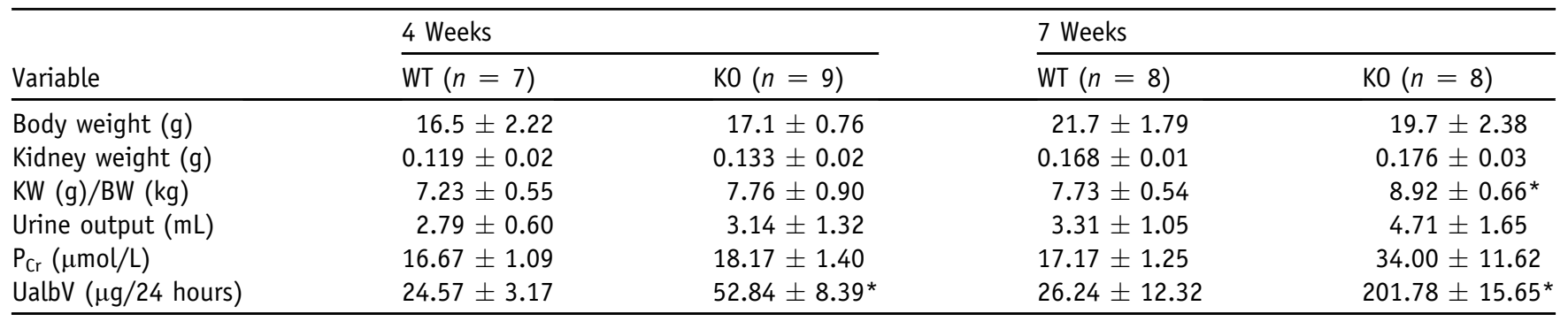

Values are means \pm SEM. BW and KW were recorded at time of sacrifice. Urine output was measured for 24 hours the day before sacrifice. $\mathrm{Cr}$ levels were measured in frozen plasma samples.

${ }^{*} P<0.05$ versus WT.

$\mathrm{BW}$, body weight; $\mathrm{K} 0$, homozygous for collagen, type IV, $\alpha 3$ gene; $\mathrm{KW}$, average kidney weight; $\mathrm{P}_{\mathrm{Cr}}$, plasma creatinine; UalbV, urine albumin over 24 hours; WT, wild-type.

\section{Chymase Activity}

Chymase activity was measured with a colorimetric assay. The measurements were performed in 96-well plates with a $100-\mu \mathrm{L}$ total volume. Briefly, $33 \mu \mathrm{L}$ of protein from tissue homogenate (renal cortex) was added to wells that contained $3 \mu \mathrm{L}$ of N-Succinyl-Ala-Ala-Pro-Phe $p$-nitroanilide (chymase substrate) and $64 \mu \mathrm{L}$ of assay buffer (Sigma-Aldrich). Samples were mixed and equilibrated to $37^{\circ} \mathrm{C}$ in the plate reader chamber (1 to 2 minutes). Absorbance was measured at $450 \mathrm{~nm}$ and normalized to protein content after subtracting blank values.

\section{Urinary ACE2 and H0-1 ELISA}

The amount of ACE2 present in urine specimens was quantified with a commercial ELISA kit according to the protocol provided by the supplier (Bluegene, Shanghai, China). A standard curve was generated by performing 1:2 serial dilutions of mouse recombinant ACE2 $(50 \mathrm{ng} / \mathrm{mL})$, provided with the kit, with the sensitivity $0.1 \mathrm{ng} / \mathrm{mL}$. The amount of ACE2 obtained by ELISA was normalized to the urine creatinine concentration, and was reported as $\mathrm{ng} / \mu \mathrm{mol}$ creatinine.

Mouse HO-1 ELISA kit (USCN Life Science Inc., Houston, TX) was used to measure urine HO-1 protein concentration. Mouse urine samples were thawed overnight at $4{ }^{\circ} \mathrm{C}$ and then centrifuged for 20 minutes at $1000 \times g$. Pellets were discarded, and urine samples were diluted twice and were assayed per the manufacturer's instructions. Final HO-1 concentrations were expressed as $\mathrm{ng} / \mathrm{mmol}$ creatinine.

\section{Cell Culture}

Primary human renal proximal tubular epithelial cells (PTECs) were purchased from Lonza Walkersville Inc. (Walkersville, MD). Cells were cultured as described before. ${ }^{11,12}$ Briefly, tubular cells were cultured in Dulbecco's Modified Eagle Medium/F12, supplemented with 17\% v/v fetal bovine serum, $10 \mathrm{ng} / \mathrm{mL}$ epidermal growth factor, $5 \mu \mathrm{g} /$ $\mathrm{mL}$ transferrin, $5 \mu \mathrm{g} / \mathrm{mL}$ insulin, $0.05 \mu \mathrm{mol} / \mathrm{L}$ hydrocortisone, $50 \mathrm{U} / \mathrm{mL}$ penicillin, and $50 \mu \mathrm{g} / \mathrm{mL}$ streptomycin. Cells were grown in T75 flasks to approximately $80 \%$ confluence. They were then serum-deprived for 18 hours and were subjected to control (serum-free medium alone), $10^{-7} \mathrm{~mol} / \mathrm{L}$ Ang II, $10^{-7}$ $\mathrm{mol} / \mathrm{L}$ Ang-II $+10^{-9} \mathrm{~mol} / \mathrm{L}$ Ang-(1-7), or $10^{-7} \mathrm{~mol} / \mathrm{L}$ Ang$\mathrm{II}+20 \mu \mathrm{mol} / \mathrm{L}$ AT-1R blocker (losartan; Sigma-Aldrich) treatments for 8 hours. Cells were then washed three times with phosphate-buffered saline, harvested, and frozen at $-80^{\circ} \mathrm{C}$ until further analysis. All cells were cultured in a humidified incubator at $37^{\circ} \mathrm{C}$ and $5 \% \mathrm{CO}_{2}$.

\section{Generation and Characterization of mrACE2}

Murine rACE2 (mrACE2) was generously donated by Dr. Gavin Yadram Oudit (The University of Alberta, Edmonton, Alberta, Canada). Briefly, the extracellular domain of murine ACE2 (amino acid residues 1 to 740) was expressed recombinantly in Chinese hamster ovary cells under serum-free conditions in a chemically defined medium. The expression product was purified to homogeneity by applying the definitive production process. Quality of the mrACE2 was tested by size exclusion chromatography-high-performance liquid chromatography with the use of a MapPac-SEC1, $5 \mu \mathrm{m}, 300 \AA$ at a flow rate of $0.25 \mathrm{~mL} / \mathrm{min}$ (APEIRON Biologics, Vienna, Austria). Integration of the signal monitored at $214 \mathrm{~nm}$ indicated a purity $>99 \%$, the signal monitored at $280 \mathrm{~nm}$ also indicated a purity $>99 \%$.

\section{Treatment with ACE Inhibitor or mrACE2}

Ramipril (Sigma-Aldrich) was added to the drinking water and replaced twice a week, starting at 4 weeks of age to $\mathrm{Col}_{4} \mathrm{a}^{-/-}$ mice for a period of 3 weeks. Ramipril remains stable in water for $>4$ days at room temperature. Daily fluid intake was measured in this 3-week period to ensure a daily dose of 10 $\mathrm{mg} / \mathrm{kg}$ per day of ramipril over the 3 -week period. $\mathrm{Col}_{4 a} 3^{-1-}$ mice were administered mrACE2 at a dose of $0.5 \mathrm{mg} / \mathrm{kg}$ per day, starting at 4 weeks of age for a period of 3 weeks, via osmotic minipump (model 1004; Alzet, Palo Alto, CA).

\section{Statistical Analysis}

Unless specified otherwise, results are expressed as means \pm SEM. Two-tailed Student's $t$-test was used for 

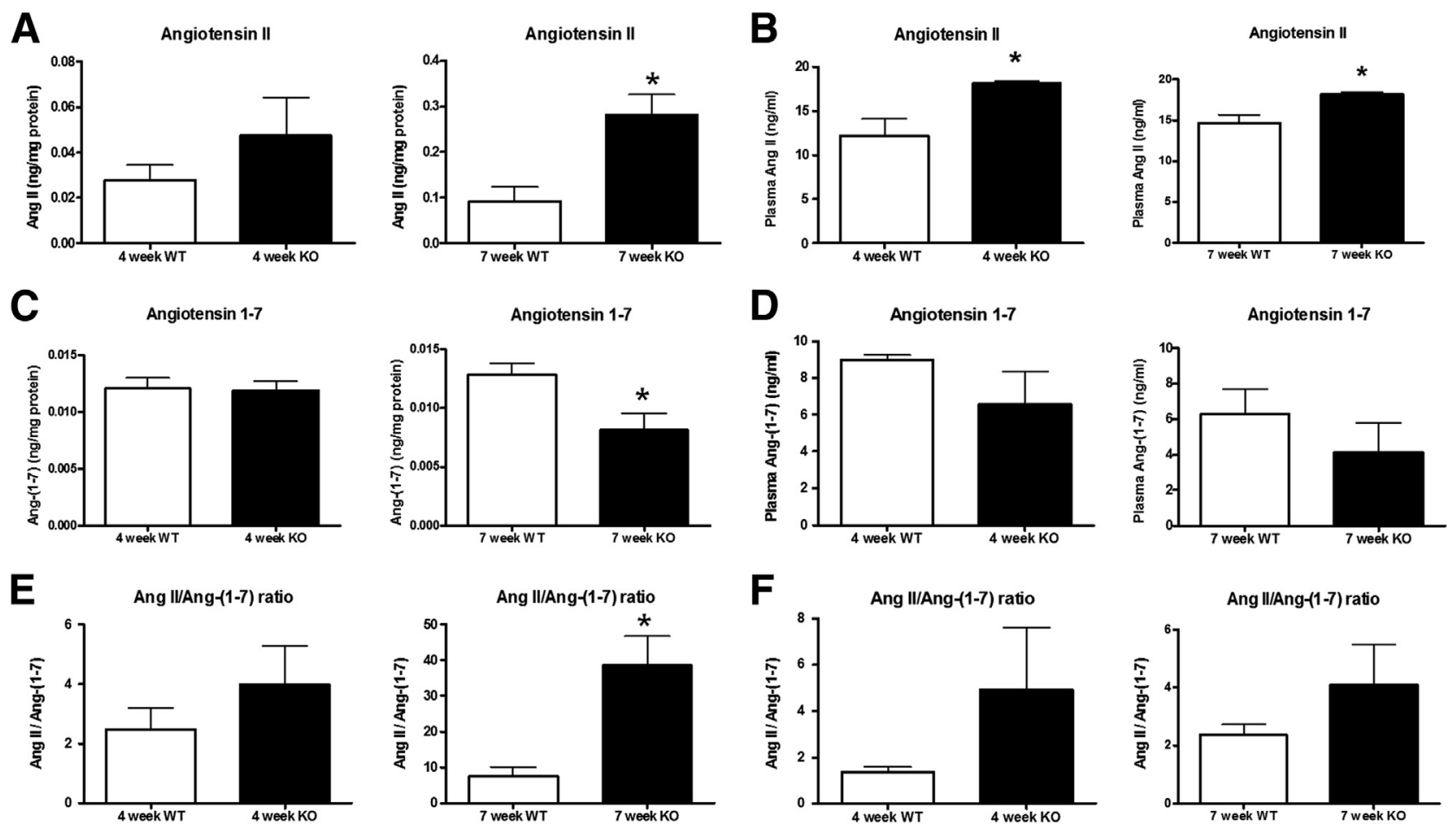

Figure 2 Ang II and Ang-(1-7) peptides in kidneys and plasma of 4- and 7-week-old WT and KO mice. Peptide levels were determined by enzyme immunoassay and normalized to total protein. Renal Ang II and Ang-(1-7) peptide levels are not different between WT and K0 mice at 4 weeks of age, whereas Ang II peptide level is significantly higher (A), and Ang-(1-7) peptide is significantly lower in 7-week-old KO compared with WT mice (C). E: Ang II/Ang(1-7) ratio is significantly increased in 7-week-old KO mice compared with 7-week-old WT mice. Plasma Ang II peptide level is significantly increased in 4- and 7-week-old KO mice compared with age-matched mice (B), but no significant differences are found in Ang-(1-7) peptide level (D) and Ang II/Ang-(1-7) ratio (F) between the same mouse groups. Data are expressed as means \pm SEM. ${ }^{*} P<0.05$ versus WT. Ang, angiotensin; K0, knockout; WT, wild-type.

comparisons between two groups. Nonparametric MannWhitney test was used to compare nonnormally distributed data (urine HO-1 protein levels between $\mathrm{Col}_{4} \mathrm{a3}^{-/-}$and WT mice). One-way analysis of variance was used for comparison of three or more groups. All statistical analyses were done with GraphPad Prism software version 5.0 (GraphPad Software, Inc., La Jolla, CA). The expression of the RAS gene signature was compared with the whole microarray gene signature by $\chi^{2}$ test. Two-tailed $P<0.05$ was considered significant.

\section{Results}

Whole Mice, Macroscopic, and Microscopic Kidney Examinations

Col4a3 $^{-/-}$mice (KO) were genotyped (Figure 1A), and microarray analysis-derived heat map for collagen-IV $\alpha 1-\alpha 5$ gene expression in kidney tissues of 4- and 7-weekold WT and $\mathrm{CollAa}^{-/-}$mice were generated (Figure 1B). As expected, Col4a3 gene expression was absent in the KO mice. Difference in expression of other collagen-IV $\alpha$ genes was most pronounced in 7-week-old mice. KO mice indicated absent $\alpha 4 / \alpha 5$ genes with increased $\alpha 1 / \alpha 2$ gene abundance compared with WT mice. Urinary albumin excretion was significantly increased even in 4-week-old $\mathrm{Col}_{4} 3^{-/-}$mice (Figure 1C). Serum creatinine levels were numerically increased in 7-week-old Col4a $3^{-/-}$mice, although the difference did not reach statistical significance $(P=0.18)$ (Figure 1D). Whole mice and biochemical data for the four groups of mice are shown in Table 1. Body weight was not different in $\mathrm{Col}_{4} 3^{-/-}$mice compared with WT mice, but kidney-to-body weight ratio increased significantly in 7-weekold Col4a $3^{-/-}$mice compared with the age-matched WT mice. Histopathologic kidney injury was evident on Periodic acid-Schiff - and Masson's trichrome-stained sections from $\mathrm{Col}_{4} \mathrm{a}^{-/-}$mice (Figure 1, E and F), particularly at 7 weeks of age.

\section{Kidney Ang II and Ang-(1-7) Peptide Levels}

Tissue Ang II and Ang-(1-7) levels were quantified with enzyme immunoassay. Ang II and Ang-(1-7) levels were not significantly different between WT and $\mathrm{Col}_{4} \mathrm{a}^{-1-}$ mice at 4 weeks of age, whereas Ang II level was significantly higher (Figure 2A) and Ang-(1-7) level was significantly lower in 7-week-old $\mathrm{ColHa}^{-/-}$mice than in WT mice (Figure 2C). An Ang II/Ang-(1-7) ratio that was used to reflect the counterbalancing nature of these peptides further reflected this pattern (Figure 2E). In the plasma, Ang II was increased in 4- and 7-week-old $\mathrm{Col}_{4 a} 3^{-/-}$mice compared with WT mice (Figure 2B). However, neither plasma Ang-(1-7) peptide level nor the Ang II/Ang-(1-7) 
A

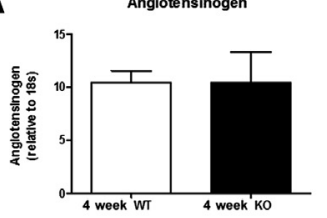

C
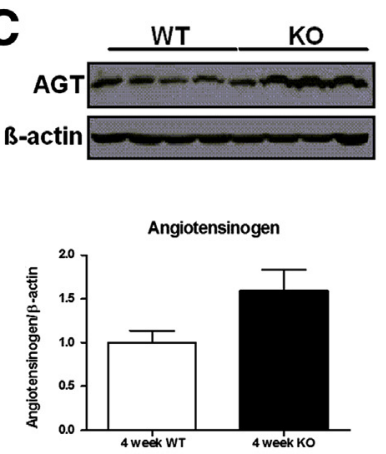
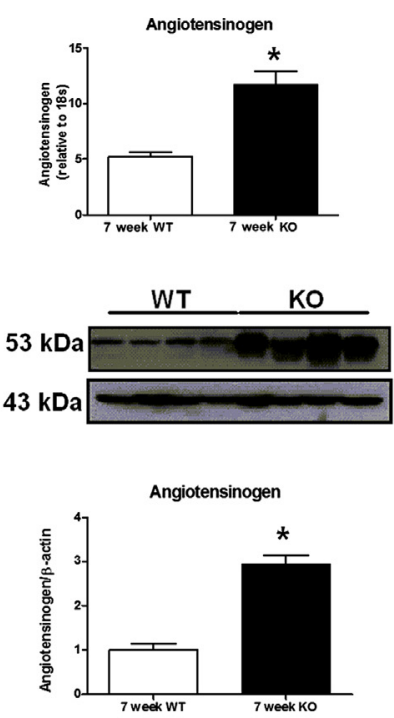

ко

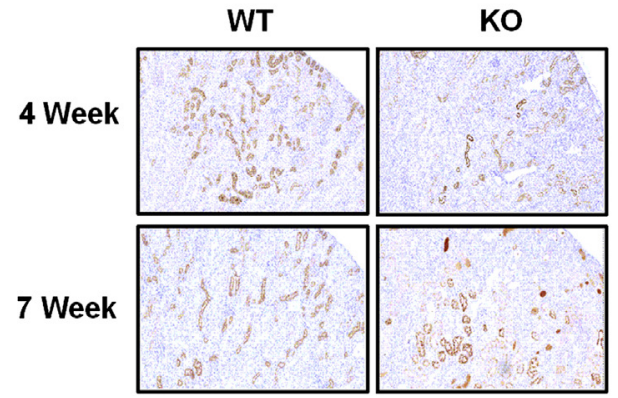

B
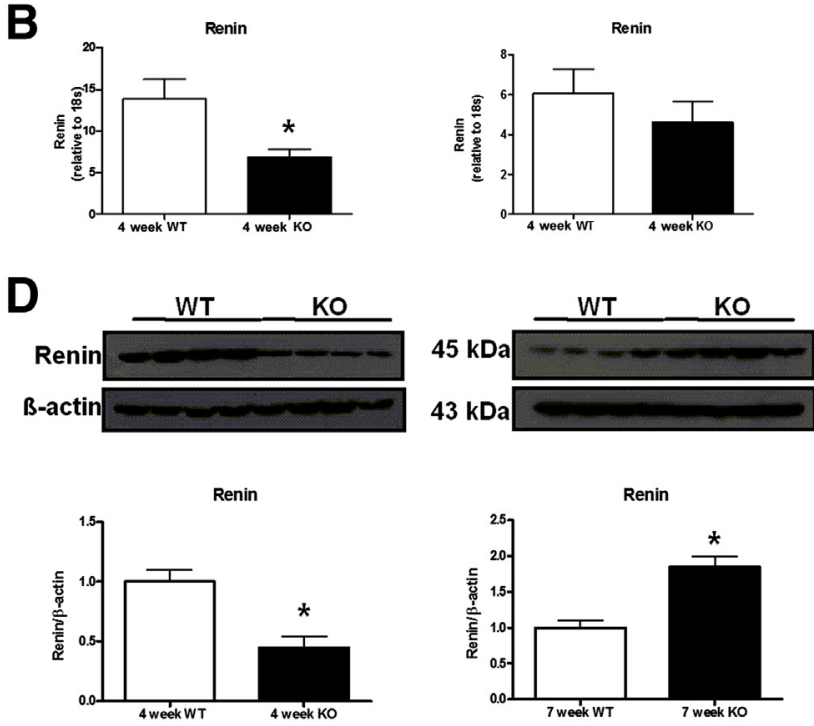

$\mathbf{F}$

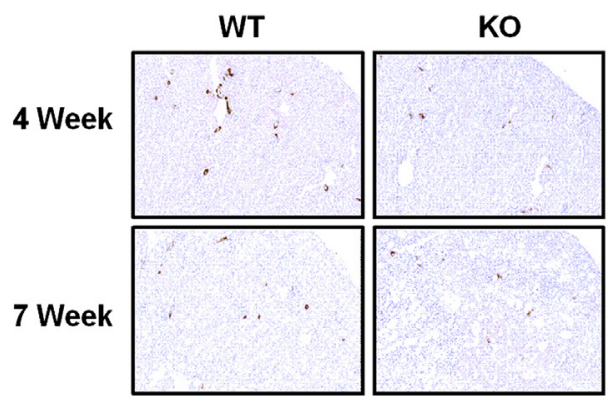

Figure 3 A: AGT and renin expression in kidneys of KO and WT mice. AGT mRNA levels increase in 7-week-old K0 mice compared with age-matched WT mice, whereas the expression is similar in 4-week-old KO and WT mice. B: Renin mRNA is decreased in 4-week-old KO mice compared with age-matched WT mice, whereas no difference is found between 7-week-old WT and KO mice. C: AGT protein expression in the kidney is significantly higher in 7-week-old K0 mice than in 7-week-old WT mice. D: Renal renin protein expression is also significantly higher in 7-week-old K0 mice than in 7-week-old WT mice, whereas renin protein expression is decreased in 4-week-old K0 mice compared with age-matched WT mice. E: AGT-positive area is markedly increased in 7-week-old K0 mice compared with 7-week-old WT mice. F: Immunostaining for renin finds predominant staining in juxtaglomerular cells, with most abundant staining visible in 4-week-old WT and 7-week-old K0 mice. Data are expressed as means \pm SEM. ${ }^{*} P<0.05$ versus WT. Original magnification, $\times 100$ (E and F). AGT, angiotensinogen; K0, knockout; WT, wild-type.

ratio were significantly different between the two groups (Figure 2, D and F).

\section{Kidney AGT and Renin Expression}

We proceeded to systematically examine the expression of RAS components in kidneys of $\mathrm{Col}_{4} \mathrm{a3}^{-/-}$and WT mice. We first examined mRNA and protein expression of the two rate-limiting components of RAS peptide generation, namely AGT and renin. Real-time PCR-based gene expression found increased AGT mRNA levels in 7-week-old $\mathrm{Col}_{4} \mathrm{a}^{-/-}$mice compared with age-matched WT mice, whereas expression was similar between 4-week-old KO and WT mice (Figure 3A). AGT protein expression paralleled gene expression (Figure 3C). Immunohistochemistry localized AGT to the proximal tubules, and expression level was consistent with the Western blot analysis (Figure 3E). Renin gene expression was significantly lower in 4-week-old $\mathrm{Col} 4 \mathrm{a}^{-/}{ }^{-}$mice than in agematched WT mice, whereas no difference was found between the groups at 7 weeks (Figure 3B). Renin protein expression indicated a similar pattern of gene expression in 4-week-old mice. At 7 weeks of age, renin protein levels were significantly higher in $\mathrm{Col}_{4 a 3^{-/}}$mice than in WT mice (Figure 3D). Renin immunohistochemistry found differences in staining intensity between the groups as seen with the Western blot analysis (Figure 3F). Renin was localized to juxtaglomerular afferent arteriolar cells, with the most prominent staining in 7-week-old $\mathrm{Coll}_{\mathrm{a} 3^{-/-}}$mice.

\section{Kidney ACE and ACE2 Expression}

We next examined renal expression of ACE and ACE2, two key enzymes in the generation of bioactive RAS peptides. Real-time PCR data indicated that ACE mRNA was significantly lower in 4-week-old $\mathrm{Col}_{4} \mathrm{a}^{-/-}$mice than in WT mice, whereas a nonsignificant trend toward lower ACE expression was found in 7-week-old $\mathrm{Col}_{4} \mathrm{a3}^{-/-}$mice than in WT mice (Figure 4A). ACE protein was significantly lower 
A

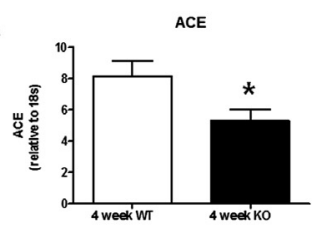

C

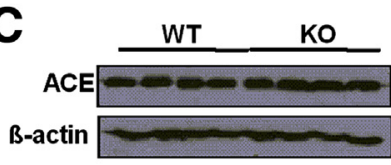

ACE

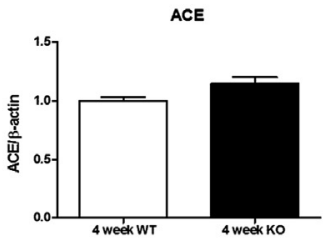

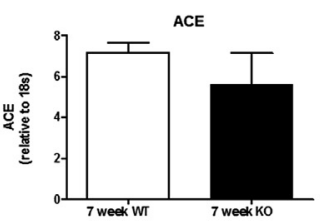

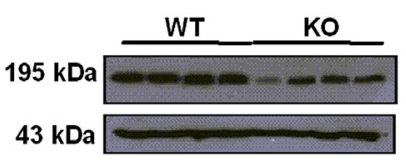

ACE

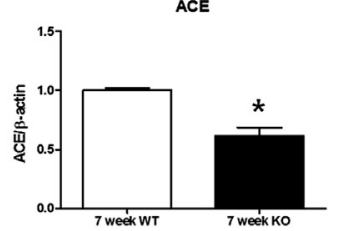

KO

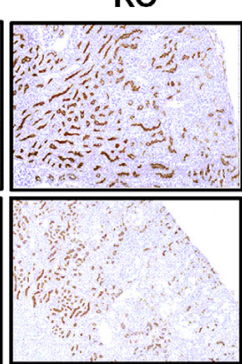

B
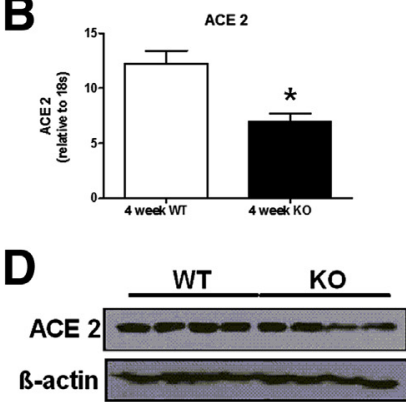

ACE 2

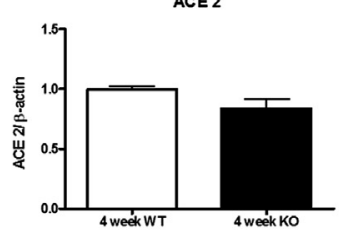

$\mathbf{F}$

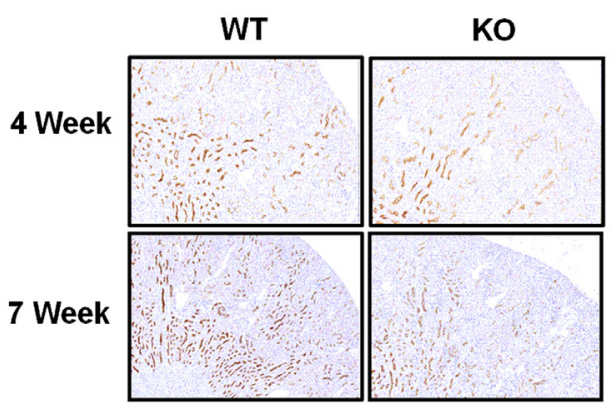

Figure 4 ACE and ACE2 expression in kidneys of WT and KO mice. A: ACE mRNA level decreases in 4-week-old K0 mice compared with age-matched WT mice, whereas the expression is similar in 7-week-old KO and WT mice. B: ACE2 mRNA level decreases in 4-week-old K0 mice compared with age-matched WT mice, whereas the expression is similar in 7-week-old KO and WT mice. C: ACE protein expression in the kidney is significantly lower in 7-week-old K0 mice than in 7-week-old WT mice. D: ACE2 protein expression in the kidney is significantly lower in 7-week-old K0 mice than in 7-week-old WT mice. E: ACE positive-area is markedly decreased in 7-week-old K0 mice compared with 7-week-old WT mice. F: ACE2 positive-area is markedly decreased in 7-week-old K0 mice compared with 7-week-old WT mice. Data are expressed as means \pm SEM. ${ }^{*} P<0.05$ versus WT. Original magnification, $\times 100(\mathbf{E}$ and $\mathbf{F})$. ACE, angiotensin-converting enzyme; K0, knockout; WT, wild-type.

in 7-week-old Col4a3 ${ }^{-/-}$mice than in WT mice, whereas no difference was found between 4-week-old Col4a3 $^{-1-}$ and WT mice (Figure 4C). ACE was localized to the proximal tubule on immunohistochemistry slides (Figure 4E). Representative images (Figure 4E) and accompanying quantification of ACEpositive area (Supplemental Figure S1A) supported the Western blot analysis-based quantification, with lowest ACE expression in 7-week-old $\mathrm{Coll}_{4} 3^{-/-}$mice.

ACE2 indicated a similar pattern of expression as ACE. ACE2 mRNA expression was significantly diminished in

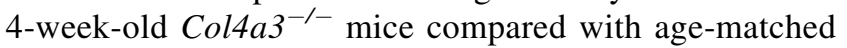
controls, whereas no difference was found in the expression between 7-week-old $\mathrm{Col}_{4} \mathrm{a}^{-1-}$ and WT mice (Figure 4B). ACE2 protein was significantly lower in 7-week-old $\mathrm{Col}_{4} a 3^{-/-}$mice than in age-matched WT mice, whereas no difference was found in the expression between 4-week-old mice (Figure 4D). ACE2 was localized to the proximal tubule on immunohistochemistry slides (Figure 4F). Representative images (Figure 4F) and accompanying quantification of ACE2-stained area (Supplemental Figure S1B) supported findings from
Western blot analyses, with lowest expression in 7-weekold $\mathrm{Col}_{4} \mathrm{a}^{-/-}$mice.

\section{ACE, ACE2, and Chymase Activity}

We found increased Ang II peptide and decreased Ang-(1-7) level in 7-week-old $\mathrm{Col}_{4 a}{ }^{-1-}$ mice compared with agematched controls but decreased expression of ACE and ACE2. We thus directed our attention to the renal enzymatic activity of ACE, ACE2, and another Ang II-generating enzyme chymase. ACE activity was not different in 7-week-old $\mathrm{Col}_{4} a 3^{-1-}$ mice compared with WT mice (Figure 5A), whereas ACE2 and chymase activity was significantly lower in 7-weekold $\mathrm{CollAa}^{-/-}$mice than in WT mice (Figure 5, B and C). Finally, ACE2 urinary excretion was significantly decreased in 7-week-old $\mathrm{Col}_{4} \mathrm{a3}^{-1-}$ mice compared with age-matched WT mice (Table 2). ACE, ACE2, and chymase activity in kidney tissue and ACE2 urine excretion were not significantly different between 4-week-old $\mathrm{Col}_{4 a 3^{-1}}$ and WT mice.

To examine whether ACE2 may regulate the expression of RAS effector peptides, we also measured renal Ang II 

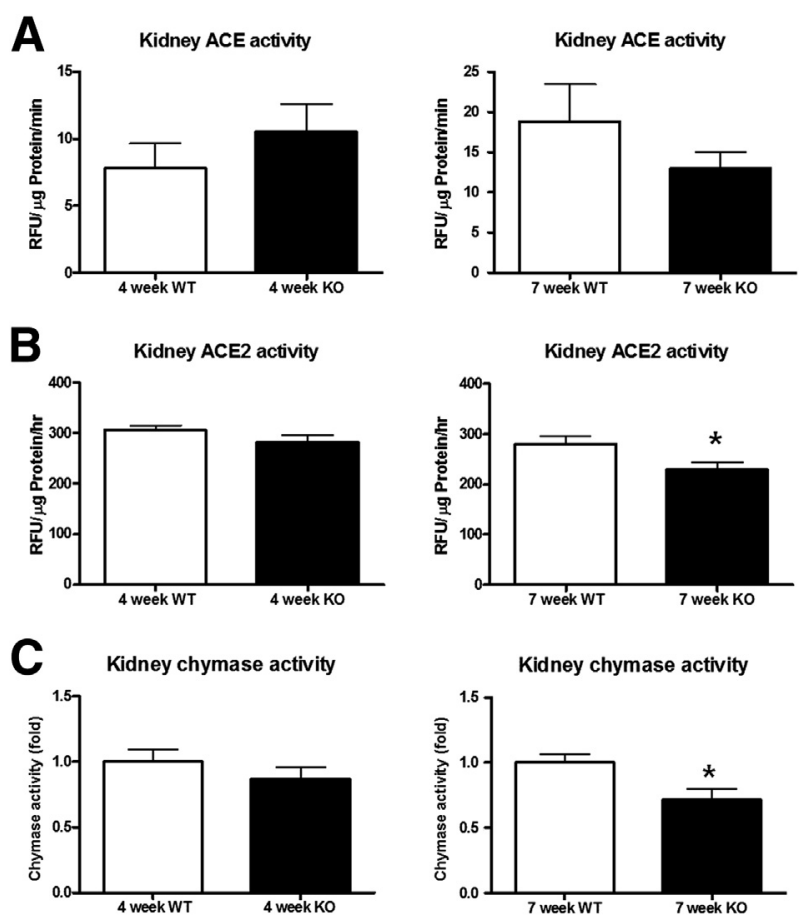

Figure 5 ACE, ACE2, and chymase enzyme activity in 4- and 7-week-old WT and KO kidney tissue. A: Tissue ACE enzyme activities (normalized to total protein) in 4- and 7-week-old K0 mice are similar compared with WT mice. B: ACE2 enzyme activity (normalized to total protein) in kidneys of 7-week-old KO mice is significantly decreased compared with age-matched WT mice. C: Chymase enzyme activity (normalized to total protein) in kidneys of 7-week-old $\mathrm{KO}$ mice is significantly decreased compared with age-matched WT mice. Data are expressed as means \pm SEM. ${ }^{*} P<0.05$ versus WT. ACE, angiotensin-converting enzyme; K0, knockout; RFU, relative fluorescence unit; WT, wild-type.

and Ang-(1-7) levels after treatment with mrACE2. Indeed, the elevated Ang II and decreased Ang-(1-7) levels seen in 7-week-old $\mathrm{Col}_{4} \mathrm{a}^{-1-}$ mice were partially reversed after mrACE2 administration (Supplemental Figure S2).

\section{Kidney AT-1 and Mas Receptor Expression}

The two dominant bioactive peptides of RAS, Ang II and Ang-(1-7), exert their main functions by activating AT-1R and MasR respectively, and so we examined the expression of these two receptors. AT-1R and MasR were not differentially expressed at the level of mRNA in 4- or 7-week-old $\mathrm{Col}_{4} 3^{-/-}$mice compared with WT mice (Figure 6A). In contrast, both AT-1R and MasR proteins were significantly

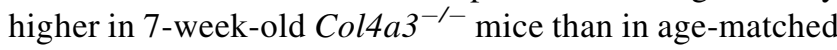

WT mice. No differences were found in receptor expres-

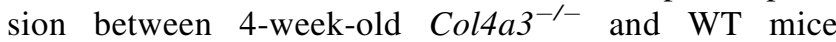
(Figure 6B).

\section{Correlation with Previously Described Markers of Intrarenal Ang II Activity}

Our data indicated dysregulation in RAS components with a significant increase in Ang II and Ang II/Ang-(1-7) ratio in the kidneys of $\mathrm{Col}_{4 a 3^{-/-}}$mice. Given the potential importance of this imbalance between the two critical effectors of RAS, it would be informative to have markers that could reflect the imbalance.

We have recently identified 83 proteins regulated by Ang II in PTECs. ${ }^{10}$ We thus examined whether the Ang II-dominant state could be reflected in the expression of these Ang II-regulated proteins. We first examined the mRNA expression of these proteins. Seventy-six of 83 proteins had corresponding mRNAs on the Affymetrix Gene Chip Mouse Gene 2.0 ST arrays (Figure 7). We performed unsupervised hierarchical cluster analysis which found that 30 of 76 genes were significantly up-regulated and 3 genes were significantly downregulated in 7-week-old $\mathrm{Col} 4 \mathrm{a}^{-/-}$mice compared with WT mice (Figure 7 and Supplemental Table S1). This number of differentially regulated genes was significantly higher than would be expected from chance alone, when comparing it with the whole Affymetrix Chip that contained 8961 of 41,345 genes that were differentially regulated in $\operatorname{Col} 4 \alpha 3^{-/-}$ compared with WT mice at false discovery rate $\leq 5 \%$ $\left(\chi^{2}\right.$ statistic, $21.11 ; P=4 \times 10^{-6}$ for the difference in proportion of differentially regulated genes in Ang II gene set and the whole Affymetrix set). One of our top candidates from previous analyses, ${ }^{10} \mathrm{HO}-1$ (gene name Hmoxl), was also up-regulated in 7-week-old $\mathrm{Col}_{4} 3^{-/-}$mice kidneys. None of the 76 genes were differentially expressed between the 4-week-old $\mathrm{ColHa}^{-/-}$and WT mice.

In addition, HO-1 protein expression was significantly upregulated in kidneys of 7 -week-old $\mathrm{Col}_{4} 3^{-1-}$ mice compared with age-matched controls (Figure 8A). We previously linked HO-1 urine excretion to HO-1 kidney expression. ${ }^{10}$ Interestingly, HO-1 urinary excretion rate was significantly increased in both 4-week-old $(P=0.0195)$ and 7-week-old $\mathrm{Col}_{4 a 3^{-/}}$ mice $(P=0.0079)$ compared with age-matched controls (Figure 8B). HO-1-positive stain was localized mainly to proximal tubules on immunohistochemistry slides (Figure 8C) and was significantly increased in 7 -week-old $\mathrm{Col}_{4} 3^{-/-}$mice (Supplemental Figure S1C).

Table 2 Urinary ACE2 Protein Excretion in 4- and 7-week-old K0 and WT Mice

\begin{tabular}{lllll}
\hline Variable & \multicolumn{2}{l}{4 Weeks } & \multicolumn{2}{l}{7 Weeks } \\
\cline { 2 - 5 } & WT $(n=5)$ & K0 $(n=5)$ & WT $(n=5)$ & K0 $(n=5)$ \\
\hline ACE2 $(\mathrm{ng} / \mu \mathrm{mol} \mathrm{Cr})$ & $8.68 \pm 0.73$ & $6.54 \pm 0.82$ & 0.92 & $4.59 \pm 0.63^{*}$ \\
\hline
\end{tabular}

Values are means \pm SEM.

${ }^{*} P<0.05$ versus WT.

ACE2, angiotensin-converting enzyme 2; Cr, creatinine; K0, knockout; WT, wild-type. 
A
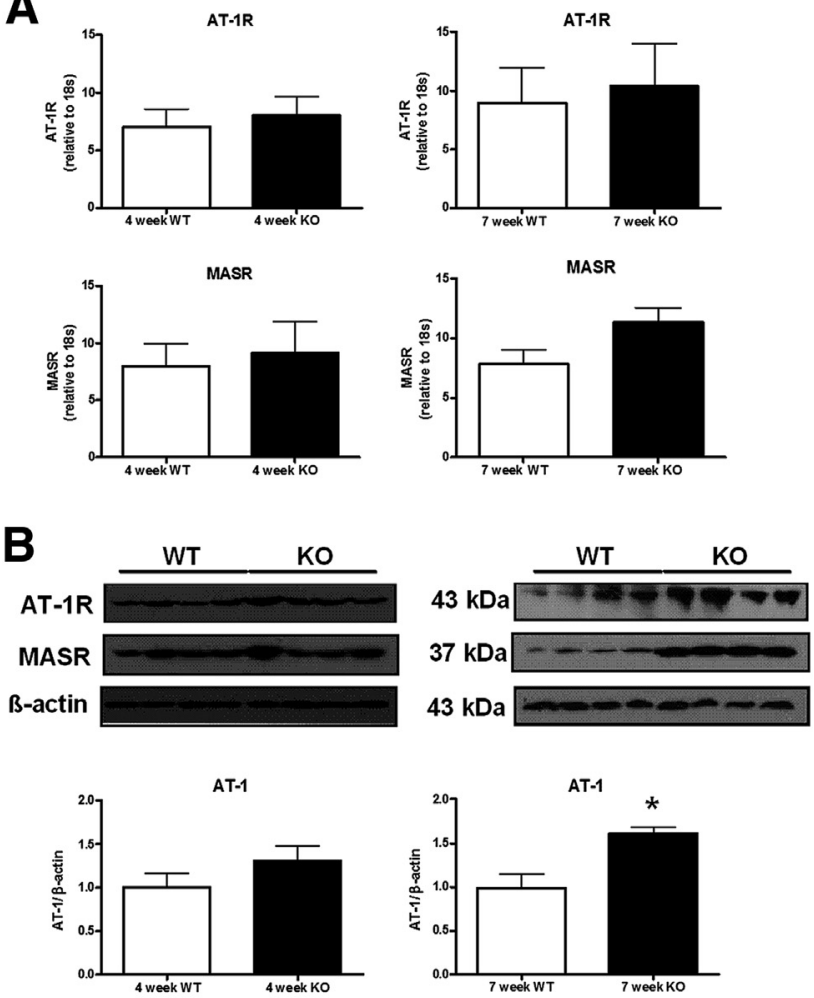

MASR
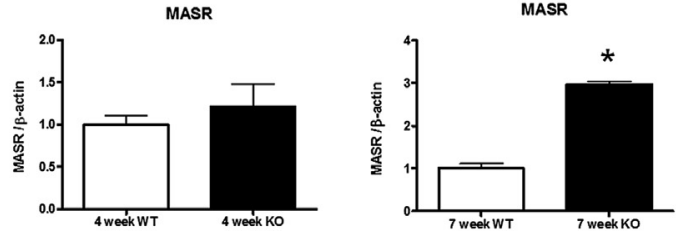

Figure 6 AT-1R and MasR expression in kidneys of WT and KO mice. A: Realtime PCR analyses indicate that AT-1R and MasR are not differentially regulated at the level of transcription in WT compared with K0 mice. B: In contrast, AT-1R and MasR protein expressions in the kidney are significantly higher in 7-week-old KO than in 7-week-old WT mice, whereas no differences are found between 4week-old WT and K0 mice. Data are expressed as means \pm SEM. ${ }^{*} P<0.05$ versus WT. AT-1R, angiotensin II type 1 receptor; K0, knockout; MasR, Mas receptor; WT, wild-type.

To ascertain whether Ang II and HO-1 are causally linked, we examined intrarenal HO-1 protein expression after treatment with an ACE inhibitor. Indeed, Western blot analyses found significantly decreased intrarenal HO-1 expression after ACE inhibitor treatment (Supplemental Figure S3, A and B). Furthermore, urinary excretion of HO-1 decreased significantly in $\mathrm{Col}_{4} \mathrm{a}^{-/-}$mice treated with the ACE inhibitor $(P=0.0017)$ (Supplemental Figure S3C).

To further delineate the effect of bioactive peptides of RAS on HO-1 expression, we examined HO-1 expression in PTECs in vitro, in response to Ang II, Ang-(1-7), and an Ang receptor antagonist (losartan). Human primary PTECs were treated with control medium, Ang II, Ang II and Ang (1-7), or Ang II and losartan for 8 hours. HO-1 protein expression was significantly increased in Ang II-treated PTECs compared with control $(P=0.0209)$ and decreased in the presence of Ang-(1-7) $(P=0.0146)$ or losartan $(P=0.0231)$ (Figure $8 \mathrm{D})$.

\section{Discussion}

Our goal was to better understand the intrarenal RAS in AS. We had the following three main aims: i) to determine the intrarenal expression of RAS components in AS compared with control mice, ii) to examine the intrarenal levels of key bioactive RAS peptides in the context of ACE2 activity, and iii) to assess whether renal expression of previously defined ${ }^{10}$ Ang II-induced genes and proteins reflects the balance of bioactive peptides of RAS in AS mice. We studied $\mathrm{Col}_{4} 3^{-/-}$mice, a well-characterized experimental model of human AS, at an age before advanced chronic injury develops. Albuminuria was present in 4-weekold $\mathrm{Col}_{4} a 3^{-1-}$ mice and progressed in 7-week-old $\mathrm{Col}_{4} a 3^{-1}$ mice, accompanied by histologic injury, including glomerulosclerosis and tubulointerstitial fibrosis.

Our first main observation was a marked increase in the renal Ang II level and a decrease in the Ang-(1-7) level in the kidneys of 7-week-old $\mathrm{Col}_{4} \mathrm{a3}^{-1-}$ mice compared with WT mice, although plasma Ang-(1-7) and Ang II/Ang-(1-7) ratio were not altered. These findings suggested that local Ang peptide processing may play a main role in AS nephropathy. We also found that both renin and AGT mRNA and protein

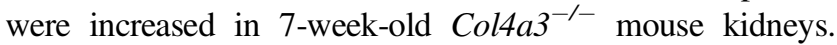
Renin is the rate-limiting enzyme for the formation of Ang I, and up-regulation could lead to enhanced Ang I generation. In addition, renin can signal through its own receptor, independently of its enzymatic activity, and this signaling was previously linked to glomerular injury and disease progression. ${ }^{11-13}$ Similarly, tubular AGT overexpression alone was linked to hypertension and progressive renal injury. ${ }^{14}$ In PTECs of diabetic mice, increased AGT expression depended on the generation of reactive oxygen species. ${ }^{15,16}$ Albuminuria is known to increase tubular oxidative stress and may be the cause of increased tubular AGT expression. ${ }^{17,18}$ More recently, Ichikawa and colleagues ${ }^{19}$ reported that liver-derived, filtered AGT was the primary source of intrarenal Ang II and contributed to the increase in renal Ang II in mice with impaired glomerular permselectivity. Although filtered AGT may contribute to Ang II formation in $\mathrm{Col}_{4} 3^{-1-}$ mice, we also observed increased mRNA expression, suggesting increased local production.

We next observed that ACE expression was decreased in the kidneys of 7-week-old Col4a $3^{-1-}$ mice compared with WT mice, although mean values for ACE activity were similar. These findings suggest that changes in ACE activity, alone, cannot account for the increased tissue Ang II peptide levels in our $\mathrm{Col}_{4 a} 3^{-/-}$mice.

We then examined the expression and activity of two other enzymes known to be involved in processing of Ang peptides. We measured chymase activity to evaluate whether the increased Ang II level in 7-week-old $\mathrm{Col}_{4 a 3^{-1}}$ mice depended on chymase activity. Chymase is a chymotrypsinlike serine protease present in the secretory granules of mast cells, but it is also expressed in normal human kidneys. ${ }^{20}$ Although Ang II formation in the kidney is mainly ACE 


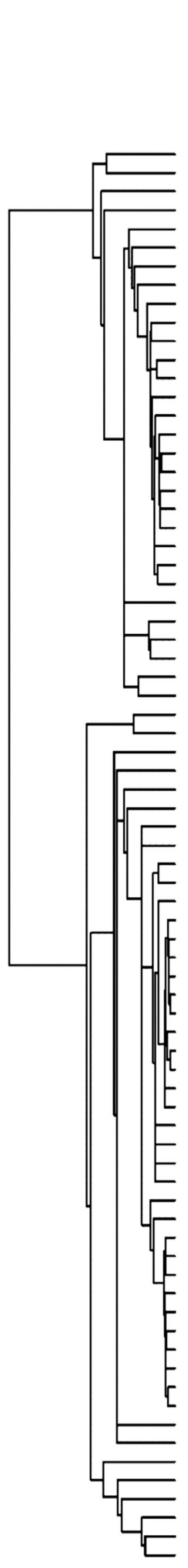

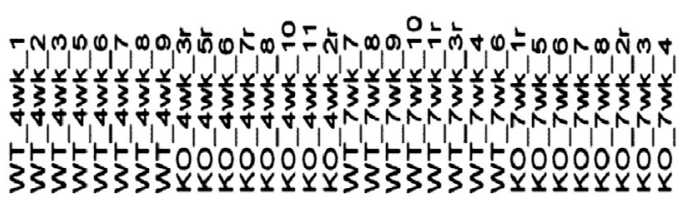

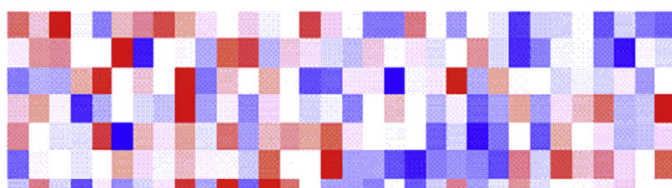

Rpl2211

Trub1

Cdc34

Dctn6

Cwc22

Kpna2

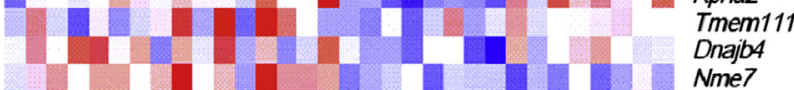

(2)
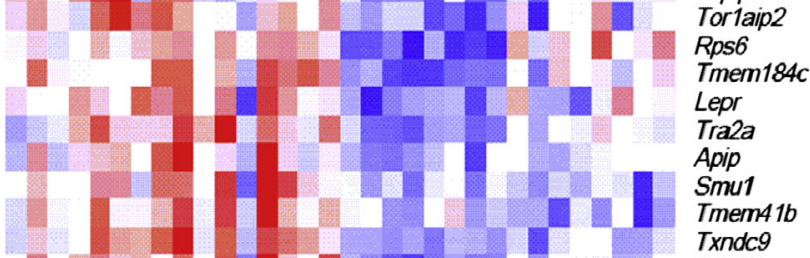

III

Efr3a

Wdr75

Cwc27

Rsf1

Fam175b

Larp4

Bag1

Hmgcs1

Rp/29

Yipf5

Eif4b

Gltscr2

Tap1
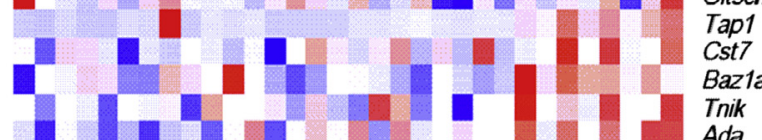

Ada

Phlda1

Pdcd4

Txnip

Arlac

Sparc

Tnfrsf10b

Lyn

Cpne2

Rhob

Fkbp10

Thbs1

Tgfbr2

Ssh3

Uck2

Nde1

Gnb4

Nin

Ctnnal1

Bst1

Eif1

Man2c1

Smyd5

Rdh10

Hmox1

Arngef2

Ext2

Ppp2r1b

Cirh1a

Egfr

Lamb2

Sic6a6

Jmjd6

Get4

Asphd1

Glul

Wbscr16

Aagab

Nup50

Kif1c
Figure 7 Heatmap of mRNA expressions of Ang II-regulated proteins in kidneys of $4-$ and

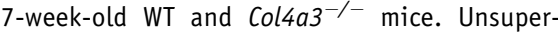
vised hierarchical cluster analysis of kidney expression of 76 Ang II-regulated genes in WT and $\mathrm{Col}_{4 a 3^{-/-}}$mice. Gene expression was performed by Affymetrix Gene Chip Mouse Gene version 2.0 ST arrays. Columns represent kidney samples, and rows represent different genes. Red color indicates increased expression relative to mean (white color), whereas blue color indicates decreased expression relative to mean. Hmox 1 is indicated by the black arrow. $n=8$ arrays per group and at each time point. Ang II, angiotensin II; Col4a3 $3^{-/}$, homozygous for collagen, type IV, $\alpha 3$ gene; Hmox1, heme oxygenase-1 gene; K0, knockout; WT, wild-type. 


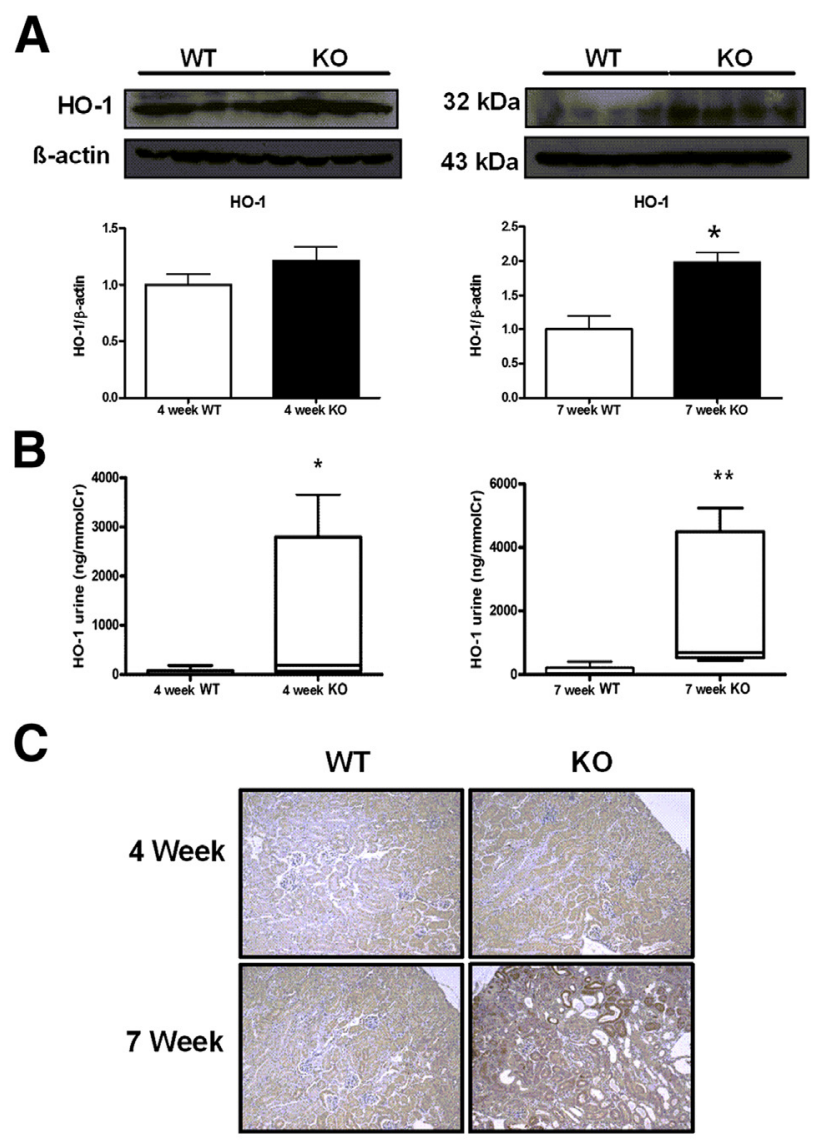

D
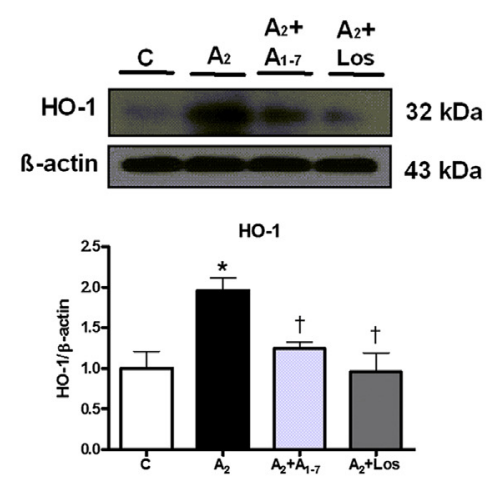

Figure $8 \mathrm{H} 0-1$ analyses in vivo and in vitro. $\mathrm{H} 0-1$ protein expressions in kidneys of WT and KO mice by Western blot analysis. A: H0-1 protein expression in the kidney is significantly higher in 7-week-old KO mice than in age-matched WT or 4-week-old mice $(P=0.0071)$. Box-and-whisker plots of H0-1 urine excretion in WT and KO mice. B: H0-1 urine excretion adjusted for $\mathrm{Cr}$ in 4- and 7-week-old mice. Immunostaining for $\mathrm{HO}-1$ indicates that $\mathrm{HO}-1$ expression is increased in 7-week-old KO mice compared with age-matched WT or 4-week-old mice. C: HO-1 was present in proximal tubules. HO-1 expression in primary human renal PTECs stimulated with Ang II and Ang-(1-7) in vitro. D: Representative Western blot analysis and densitometry of PTECs stimulated with control, $A_{2}, A_{2}+A_{1-7}$, or $A_{2}+$ Los for 8 hours. Data are expressed as means \pm SEM. $n=6$ in the K0 group (B); $n=5$ in the WT group (B); $n=3$ in each group (D). ${ }^{*} P<0.05,{ }^{* *} P<0.01$ versus control; ${ }^{\dagger} P<0.05$ versus Ang II-treated cells. Original magnification, $\times 100$ (C). Ang, angiotensin; $A_{2}$, Ang II; $A_{2}+A_{1-7}$, Ang II + Ang-(1-7); $A_{2}+$ Los, Ang II + losartan; $C$ r, creatinine; H0-1, heme oxygenase-1; K0, knockout; PTEC, proximal tubular epithelial cell; WT, wild-type. dependent, a role for chymase was also reported. Chymase expression was faintly detectable in the glomeruli and vascular smooth muscle cells of normal human kidneys, whereas it was markedly up-regulated in kidneys of diabetic patients. ${ }^{20}$ Moreover, it was found that mesangial cells in culture express chymase mRNA, and that its expression is increased by high glucose stimulation. ${ }^{21}$ Chymase-dependent Ang II formation plays an important role in the development of vascular proliferation in the grafted veins. ${ }^{22}$ However, we found chymase activity to be decreased in 7-week-old Col4a3 $3^{-1-}$ mice compared with age-matched WT mice.

We next focused on ACE2. ACE2 is a monocarboxy peptidase that cleaves Ang I and Ang II to generate Ang-(1-9) and Ang-(1-7), respectively, and is 400-fold more efficient at metabolizing Ang II than Ang I. It plays a significant role in the degradation of Ang II and the generation of Ang-(1-7). ${ }^{23}$ ACE2 attenuates the biological effects of Ang II by both reducing Ang II concentrations and increasing Ang-(1-7) concentrations. Thus, ACE2 deletion worsens Ang II-induced hypertension in mice. ${ }^{20}$ In addition, we and others reported that ACE2 deletion or pharmacologic blockade accelerated diabetic kidney injury and Ang II-induced kidney inflammation and fibrosis. ${ }^{21,22}$ Moreover, Ang II was able to up-regulate ACE and down-regulate ACE2 in human kidney tubular cells. ${ }^{24}$ Consistently, a recent study reported that elevated Ang II levels stimulated ACE2 lysosomal degradation, thereby reducing its expression and activity. ${ }^{25}$ Several studies suggest that inhibition of Ang II formation or AT-1R signaling leads to increased ACE2 levels in vivo. ${ }^{26-28}$ ACE2 deletion in mice subjected to unilateral ureteral obstruction results in increased Ang II levels, decreased Ang-(1-7) levels, and exaggerated kidney inflammation and fibrosis. ${ }^{8}$ In addition, Ang II increases ACE2 shedding in reactive oxygen species-dependent manner in cardiac tissue, ${ }^{29}$ suggesting that a similar mechanism might be operative in kidney tissue. Increased proteinuria might induce proximal tubule reactive oxygen species generation and reactive oxygen species-dependent tumor necrosis factor- $\alpha$ convert enzyme might induce ACE2 shedding, although our work does not support this mechanism on the basis of decreased, rather than increased urinary excretion of ACE2. Thus, decreased ACE2 protein expression and increased Ang II peptide level in the kidney may be associated with proteinuria. To determine whether ACE2 may regulate the expression of these RAS components, we examined Ang II and Ang-(1-7) peptide levels after mrACE2 treatment. mrACE2 treatment partially corrected Ang II and Ang-(1-7) peptide levels in AS nephropathy mice. Therefore, our study suggests that the increased renal Ang II level and decreased Ang-(1-7) level in 7-week-old $\mathrm{ColHa}^{-1-}$ mice were associated with decreased renal ACE2 expression and activity and could be corrected, at least in part, by administration of mrACE2.

Studies have reported that the urinary excretion rate of ACE2 is increased in humans and mice with diabetes. ${ }^{30,31} \mathrm{In}$ $\mathrm{db} / \mathrm{db}$ mice, increased urinary excretion rate parallels kidney ACE2 activity. ${ }^{30}$ In accord with the changes in protein expression and ACE2 activity, we found that urinary ACE2 
excretion was decreased in our 7-week-old $\mathrm{Col}_{4 a 3^{-1-}}$ mice compared with age-matched controls. Taken together these findings suggest that kidney ACE2 expression is reflected in urinary excretion rate.

Ang-(1-7) levels were significantly reduced in 7-weekold $\mathrm{Col}_{4} \mathrm{a}^{-1-}$ mice compared with WT mice, also in keeping with the low ACE2 expression and activity. Ang$(1-7)$ has vasodilatory, natriuretic, and antiproliferative actions, ${ }^{32}$ and it counterbalances the effects of Ang II. The ratio of Ang II/Ang-(1-7) was significantly increased, suggesting that Ang II-mediated effects would predominate in the kidneys of 7-week-old $\mathrm{ColHa}^{-/-}$mice. The importance of Ang II/Ang-(1-7) ratio was highlighted in previous studies. ${ }^{33}$ Our observations suggest that the decrease in ACE2 activity not only contributed to increased Ang II levels but also led to a decline in renal Ang-(1-7) levels and that both of these effects may contribute to progressive kidney injury in this model of AS.

We also found that the main receptors for Ang II and Ang-(1-7), AT-1R and MasR, respectively, were overexpressed in 7-week-old $\mathrm{Col}_{4 a 3^{-/}}$mice. AT-1R expression was found to be critical for the development of hypertension, ${ }^{34}$ and its overexpression may indicate increased activation. MasR gene deletion was associated with loss of glomerular permselectivity. ${ }^{35}$ Increased expression of the MasR in $\mathrm{Col}_{4 a} 3^{-1-}$ mice could reflect compensation for decreased Ang-(1-7) generation. Accumulating evidence suggests that the balance between the ACE/Ang II/AT-1R versus the ACE2/Ang-(1-7)/MasR axes determines the final output of RAS activity, and increased expression of the receptors might be associated with increased tissue sensitivity to the effector peptides.

Increased renal Ang II peptide level and the loss of the counterbalancing Ang-(1-7) was also reflected in our measures of an Ang II signature that we recently defined in PTECs..$^{10}$ Our third main observation was that an Ang II gene signature set was overexpressed in kidneys of 7-week-old $\mathrm{Col}_{4} 3^{-/-}$mice. Renal HO-1 protein expression, an important component of the Ang II gene signature, ${ }^{36,37}$ was increased in 7-week-old $\mathrm{Col}_{4 a 3^{--}}$mice, and this increase was abolished with ACE inhibition. We have reported that Ang II up-regulates renal HO-1 in an AT-1R-dependent manner and that the increase in kidney expression is reflected in the urinary excretion rate of HO- $1 .{ }^{10}$ Consistently, the urinary excretion rate of HO- 1 was increased in 7- and 4-week-old $\mathrm{Col}_{4} \mathrm{a}^{-/-}$mice but dramatically diminished in ACE inhibitor-treated $\mathrm{Col}_{4} \mathrm{a}^{-/-}$mice. The urinary excretion rate of HO-1 may represent an early marker of renal injury and RAS dysregulation in the kidney. Moreover, our in vitro studies found that HO-1 expression in PTECs is regulated by both Ang II and Ang-(1-7) and may be AT-1R dependent. This is consistent with our notion that reduced ACE2 expression and activity led to an increase in Ang II and a reduction in Ang-(1-7) levels in the kidneys of the $\mathrm{Col}_{4} \mathrm{a}^{-/-}$mice and that both of these effects contributed to the increase in renal expression of Ang II-induced genes.

\section{Conclusion}

The early phase of kidney injury in mice with experimental AS is associated with marked changes in expression of components of the RAS in the kidney. Although RAS probably does not initiate injury in this model, based on histopathologic injury and proteinuria at 4 weeks of age, it is activated soon after the initial injury and is a significant driver of disease progression. Reduced ACE2 expression and activity contributes to altered Ang peptide levels, including an increase in Ang II and a decrease in Ang-(1-7) kidney levels, likely contributing to progressive renal injury. ACE2 and HO-1 may serve as markers of AS kidney injury, and administration of ACE2 and/or Ang-(1-7) may represent novel therapeutic approaches to AS.

\section{Acknowledgment}

mrACE2 was a gift from Dr. Gavin Yadram Oudit (The University of Alberta).

\section{Supplemental Data}

Supplemental material for this article can be found at http://dx.doi.org/10.1016/j.ajpath.2015.01.021.

\section{References}

1. Alport AC: Hereditary Familial Congenital Haemorrhagic Nephritis Br Med J 1927, 1:504-506

2. Flinter FA, Cameron JS, Chantler C, Houston I, Bobrow M: Genetics of classic Alport's syndrome. Lancet 1988, 2:1005-1007

3. Kashtan CE, Gubler MC, Sisson-Ross S, Mauer M: Chronology of renal scarring in males with Alport syndrome. Pediatr Nephrol 1998, $12: 269-274$

4. Hudson BG, Reeders ST, Tryggvason K: Type IV collagen: structure, gene organization, and role in human diseases. Molecular basis of Goodpasture and Alport syndromes and diffuse leiomyomatosis. J Biol Chem 1993, 268:26033-26036

5. Remuzzi A, Fassi A, Bertani T, Perico N, Remuzzi G: ACE inhibition induces regression of proteinuria and halts progression of renal damage in a genetic model of progressive nephropathy. Am J Kidney Dis 1999, 34:626-632

6. Webb NJ, Shahinfar S, Wells TG, Massaad R, Gleim GW, McCrary Sisk C, Lam C: Losartan and enalapril are comparable in reducing proteinuria in children with Alport syndrome. Pediatr Nephrol 2013, 28:737-743

7. Fang F, Liu GC, Zhou X, Yang S, Reich HN, Williams V, Hu A Pan J, Konvalinka A, Oudit GY, Scholey JW, John R: Loss of ACE2 exacerbates murine renal ischemia-reperfusion injury. PLoS One 2013 , 8:e71433

8. Liu Z, Huang XR, Chen HY, Penninger JM, Lan HY: Loss of angiotensin-converting enzyme 2 enhances TGF-beta/Smad-mediated renal fibrosis and NF-kappaB-driven renal inflammation in a mouse model of obstructive nephropathy. Lab Invest 2012, 92:650-661

9. Oudit GY, Liu GC, Zhong J, Basu R, Chow FL, Zhou J, Loibner H, Janzek E, Schuster M, Penninger JM, Herzenberg AM, Kassiri Z, Scholey JW: Human recombinant ACE2 reduces the progression of diabetic nephropathy. Diabetes 2010, 59:529-538 
10. Konvalinka A, Zhou J, Dimitromanolakis A, Drabovich AP, Fang F, Gurley S, Coffman T, John R, Zhang SL, Diamandis EP, Scholey JW: Determination of an angiotensin II-regulated proteome in primary human kidney cells by stable isotope labeling of amino acids in cell culture (SILAC). J Biol Chem 2013, 288:24834-24847

11. Huang Y, Wongamorntham S, Kasting J, McQuillan D, Owens RT, Yu L, Noble NA, Border W: Renin increases mesangial cell transforming growth factor-betal and matrix proteins through receptormediated, angiotensin II-independent mechanisms. Kidney Int 2006, 69:105-113

12. Ichihara A, Hayashi M, Kaneshiro Y, Suzuki F, Nakagawa T, Tada Y, Koura Y, Nishiyama A, Okada H, Uddin MN, Nabi AH, Ishida Y, Inagami T, Saruta T: Inhibition of diabetic nephropathy by a decoy peptide corresponding to the "handle" region for nonproteolytic activation of prorenin. J Clin Invest 2004, 114:1128-1135

13. Krebs C, Hamming I, Sadaghiani S, Steinmetz OM, MeyerSchwesinger C, Fehr S, Stahl RA, Garrelds IM, Danser AH, van Goor H, Contrepas A, Nguyen G, Wenzel U: Antihypertensive therapy upregulates renin and (pro)renin receptor in the clipped kidney of Goldblatt hypertensive rats. Kidney Int 2007, 72:725-730

14. Sachetelli S, Liu Q, Zhang SL, Liu F, Hsieh TJ, Brezniceanu ML, Guo DF, Filep JG, Ingelfinger JR, Sigmund CD, Hamet P, Chan JS: RAS blockade decreases blood pressure and proteinuria in transgenic mice overexpressing rat angiotensinogen gene in the kidney. Kidney Int 2006, 69:1016-1023

15. Brezniceanu ML, Liu F, Wei CC, Tran S, Sachetelli S, Zhang SL, Guo DF, Filep JG, Ingelfinger JR, Chan JS: Catalase overexpression attenuates angiotensinogen expression and apoptosis in diabetic mice. Kidney Int 2007, 71:912-923

16. Godin N, Liu F, Lau GJ, Brezniceanu ML, Chenier I, Filep JG, Ingelfinger JR, Zhang SL, Chan JS: Catalase overexpression prevents hypertension and tubular apoptosis in angiotensinogen transgenic mice. Kidney Int 2010, 77:1086-1097

17. Reich H, Tritchler D, Herzenberg AM, Kassiri Z, Zhou X, Gao W, Scholey JW: Albumin activates ERK via EGF receptor in human renal epithelial cells. J Am Soc Nephrol 2005, 16:1266-1278

18. Hsieh TJ, Zhang SL, Filep JG, Tang SS, Ingelfinger JR, Chan JS: High glucose stimulates angiotensinogen gene expression via reactive oxygen species generation in rat kidney proximal tubular cells. Endocrinology 2002, 143:2975-2985

19. Matsusaka T, Niimura F, Shimizu A, Pastan I, Saito A, Kobori H, Nishiyama A, Ichikawa I: Liver angiotensinogen is the primary source of renal angiotensin II. J Am Soc Nephrol 2012, 23:1181-1189

20. Gurley SB, Allred A, Le TH, Griffiths R, Mao L, Philip N, Haystead TA, Donoghue M, Breitbart RE, Acton SL, Rockman HA, Coffman TM: Altered blood pressure responses and normal cardiac phenotype in ACE2-null mice. J Clin Invest 2006, 116:2218-2225

21. Wong DW, Oudit GY, Reich H, Kassiri Z, Zhou J, Liu QC, Backx PH, Penninger JM, Herzenberg AM, Scholey JW: Loss of angiotensinconverting enzyme-2 (Ace2) accelerates diabetic kidney injury. Am J Pathol 2007, 171:438-451

22. Soler MJ, Wysocki J, Ye M, Lloveras J, Kanwar Y, Batlle D: ACE2 inhibition worsens glomerular injury in association with increased ACE expression in streptozotocin-induced diabetic mice. Kidney Int 2007, 72:614-623
23. Rice GI, Thomas DA, Grant PJ, Turner AJ, Hooper NM: Evaluation of angiotensin-converting enzyme (ACE), its homologue ACE2 and neprilysin in angiotensin peptide metabolism. Biochem J 2004, 383:45-51

24. Koka V, Huang XR, Chung AC, Wang W, Truong LD, Lan HY: Angiotensin II up-regulates angiotensin I-converting enzyme (ACE), but down-regulates ACE2 via the AT1-ERK/p38 MAP kinase pathway. Am J Pathol 2008, 172:1174-1183

25. Deshotels MR, Xia H, Sriramula S, Lazartigues E, Filipeanu CM: Angiotensin II mediates angiotensin converting enzyme type 2 internalization and degradation through an angiotensin II type I receptordependent mechanism. Hypertension 2014, 64:1368-1375

26. Ali Q, Wu Y, Hussain T: Chronic AT2 receptor activation increases renal ACE2 activity, attenuates AT1 receptor function and blood pressure in obese Zucker rats. Kidney Int 2013, 84:931-939

27. Ferrario CM, Jessup J, Gallagher PE, Averill DB, Brosnihan KB, Ann Tallant E, Smith RD, Chappell MC: Effects of renin-angiotensin system blockade on renal angiotensin-(1-7) forming enzymes and receptors. Kidney Int 2005, 68:2189-2196

28. Dilauro M, Zimpelmann J, Robertson SJ, Genest D, Burns KD: Effect of ACE2 and angiotensin-(1-7) in a mouse model of early chronic kidney disease. Am J Physiol Renal Physiol 2010, 298:F1523-F1532

29. Patel VB, Clarke N, Wang Z, Fan D, Parajuli N, Basu R, Putko B, Kassiri Z, Turner AJ, Oudit GY: Angiotensin II induced proteolytic cleavage of myocardial ACE2 is mediated by TACE/ADAM-17: a positive feedback mechanism in the RAS. J Mol Cell Cardiol 2014, 66: 167-176

30. Xiao F, Hiremath S, Knoll G, Zimpelmann J, Srivaratharajah K, Jadhav D, Fergusson D, Kennedy CR, Burns KD: Increased urinary angiotensin-converting enzyme 2 in renal transplant patients with diabetes. PLoS One 2012, 7:e37649

31. Wysocki J, Garcia-Halpin L, Ye M, Maier C, Sowers K, Burns KD, Batlle D: Regulation of urinary ACE2 in diabetic mice. Am J Physiol Renal Physiol 2013, 305:F600-F611

32. Santos RA, Campagnole-Santos MJ, Andrade SP: Angiotensin-(1-7): an update. Regul Pept 2000, 91:45-62

33. Vilas-Boas WW, Ribeiro-Oliveira A Jr, Pereira RM, Ribeiro Rda C, Almeida J, Nadu AP, Simões e Silva AC, dos Santos RA: Relationship between angiotensin-(1-7) and angiotensin II correlates with hemodynamic changes in human liver cirrhosis. World J Gastroenterol 2009, $15: 2512-2519$

34. Crowley SD, Gurley SB, Coffman TM: AT(1) receptors and control of blood pressure: the kidney and more. Trends Cardiovasc Med 2007, 17:30-34

35. Pinheiro SV, Ferreira AJ, Kitten GT, da Silveira KD, da Silva DA, Santos SH, Gava E, Castro CH, Magalhaes JA, da Mota RK, BotelhoSantos GA, Bader M, Alenina N, Santos RA, Simoes e Silva AC: Genetic deletion of the angiotensin-(1-7) receptor Mas leads to glomerular hyperfiltration and microalbuminuria. Kidney Int 2009, 75:1184-1193

36. Haugen EN, Croatt AJ, Nath KA: Angiotensin II induces renal oxidant stress in vivo and heme oxygenase-1 in vivo and in vitro. Kidney Int 2000, 58:144-152

37. Aizawa T, Ishizaka N, Taguchi J, Nagai R, Mori I, Tang SS, Ingelfinger JR, Ohno M: Heme oxygenase-1 is upregulated in the kidney of angiotensin II-induced hypertensive rats : possible role in renoprotection. Hypertension 2000, 35:800-806 